Error! No text of specified style in document. The Impact of a Materialistic Value Orientation on Well-Being

\title{
The Impact of a Materialistic Value Orientation on Well-Being
}

\section{Helga Dittmar and Megan Hurst}

If we take a longer look at human well-being, rather than a snapshot, what is most striking is that mental health problems have steadily increased over the last 80 years. Cross-temporal metaanalyses of data from over 75,000 students in the United States collected since 1938 find large generational increases in depression and other forms of psychopathology, with five times as many now scoring above established cut-off points (Twenge et al., 2010). Of course, there are many reasons for this deterioration in mental health, also recorded in other economically developed countries, including the United Kingdom where depression and anxiety in adolescents have increased by $70 \%$ since the 1980s (Young Minds at www.youngminds.org.uk). The largescale US analysis is compelling, not only because it spans such a long time, but also because it tested several factors that may be particularly significant causes of mental ill health. Periods of economic recession and boom were not found to be significant influences, nor changes in stigma attached to reporting, and seeking treatment for, mental health problems. The results best fit a model of cultural shifts towards extrinsic values, such as materialism and status, and away from intrinsic values such as community involvement, meaning in life, and close relationships. Alongside rising psychopathology, the percentage of young adults who reported wealth, expensive possessions, and status as essential long-term life goals increased dramatically, rising from below $30 \%$ to over $75 \%$, while the importance of other goals dwindled away. 
Error! No text of specified style in document. The Impact of a Materialistic Value Orientation on Well-Being

Taking a historical perspective, the core of Cushman's (1985) seminal analysis of the emergence of an "empty self" as a socio-cultural phenomenon in developed mass consumer societies is that

the post-World War II empty self . . is soothed and made cohesive by becoming "filled up" with food, consumer products, and celebrities. ... The two professions most responsible for healing the empty self, advertising and psychotherapy, find themselves in a bind: They must treat a psychological symptom without being able to address its historical causes. Both circumvent the bind by employing the life-style solution, a strategy that attempts to heal by covertly filling the empty self with the accoutrements, values, and mannerisms of idealized figures.

This analysis foreshadows the development of a social psychological perspective on negative self-appraisal linked to a materialistic value orientation as a form of psychological imprisonment, a "cage within" where individuals attempt to construct an identity through material goods that ends up as a psychological state where the self is non-authentic:

The impact of the material "Good Life" and "Body Perfect" ideals on individuals" identity and well-being . . is often negative. Thus, instead of supposedly empowering and liberating people through greater spending power, greater choice of consumer goods, and greater self-expression through consumption, consumer culture also means entrapment, and possibly entrapment of the worst kind, because people tend to be unaware of its pervasive influence . . the pursuit of these ideals often means damage to their psychological, and even physical, health. In short, consumer culture can become a "cage within," its bars invisible and its power pernicious.

(Dittmar, 2007, p. 23) 
Error! No text of specified style in document. The Impact of a Materialistic Value Orientation on Well-Being

In this chapter, our aims are threefold: First, to summarize the psychological frameworks that have theorized why and how a materialistic value orientation, or MVO for short, has an impact on well-being. Second, to review and synthesize the substantial body of research in psychology and closely related disciplines that provides a growing base of evidence for the impact of MVO on personal, social, consumer, and ecological well-being. And last, but not least, to reflect on a future research agenda that is conducive to providing an extended evidence case for improved understanding of how MVO affects adults as well as children, and for aiding in the development of psychological and policy interventions to curb MVO.

\section{Materialistic Value Orientation (MVO)}

A materialistic value orientation is a particular, precise, psychological construct and therefore not synonymous with materialism in a broader philosophical sense. Materialism refers to a set of complex, contested, and multi-faceted constructs that differ by discipline. For example, in philosophy and political science, we find debates on materialism versus idealism (Hegel, 1807; Marx, 1867), and in sociology and social theory, materialism has been discussed as the satisfaction of human material needs, such as food and shelter, as opposed to post-materialism referring to human needs for self-expression and a sense of belonging (ㅍglehart, 1990), similar to the hierarchy of needs proposed by Maslow (1943).

Instead, by MVO, we mean a person's “long-term endorsement of values, goals, and associated beliefs that center on the importance of acquiring money and possessions that convey status" (Dittmar, Bond, Hurst, \& Kasser, 2014, p. 880). Central to MVO, then, is not only the striving for money and expensive goods, but also an associated set of beliefs about the 
Error! No text of specified style in document. The Impact of a Materialistic Value Orientation on Well-Being

psychological and social benefits these goals are expected to bring with them, such as image, recognition, status, and greater happiness. MVO can be measured by questionnaire scales that have well-documented face and construct validity as well as excellent psychometric properties. In consumer and marketing research, the scale best reflecting our definition and most widely used is the Material Values Scale (Richins \& Dawson, 1992; Richins, 2004). In psychology, the Aspirations Index has been more prominent, where MVO is the relative importance of wealth, fame, and image as (extrinsic) life goals compared to other (intrinsic) life goals, such as community involvement, personal relationships, and self-development (Kasser \& Ryan, 1993; www.selfdeterminationtheory.org). In the Children's Consumer Culture Project, with over 2,000 children in the UK (www.sussex.ac.uk/Psychology/consumercultureproject/), we developed a materialistic value internalization scale based on interviews with children (Wright, Hurst, Dittmar, \& Banerjee, 2017) that is suitable for children as young as 8 years, as well as adolescents and adults (Easterbrook, Wright, Dittmar, \& Banerjee, 2014).

MVO is one psychological orientation that people have towards money and material goods, but it is certainly not the only possible orientation. Material possessions can, and do, function as an extended part of a person's sense of self and positively help in identity construction and maintenance (Dittmar, 1992). People's accounts of the meanings and functions of treasured personal possessions clearly show how material objects can symbolize landmarks in their personal history (new career, travel mementos, certificates or trophies of achievement); can express and remind them of close personal relationships (photos, gifts, heirlooms); and can make them smile, lift their mood, and/or give reassurance when they look at them or touch them. Such personal possessions help them experience continuity, uniqueness, and connectedness in their sense of self-identity (ittmar, 2011). Goffman's classic writings $(\underline{1961}, \underline{1968})$ show how 
Error! No text of specified style in document. The Impact of a Materialistic Value Orientation on Well-Being

inmates in psychiatric or penal institutions experienced identity loss when stripped of all personal possessions and made to wear a uniform, a technique still used in Guantanamo Bay or Abu Ghraib prisons. Taking particularly important personal possessions with us through major life transitions, such as moving into a new home or emigrating to a different country, is helpful for maintaining a sense of who we are as well as for adjusting to our new circumstances. Compared to people who have to give up their personal possessions when moving into an old age care home, people who can take a selection of what they most treasure with them are happier, feel less helpless, and adapt better to this major life change (Wapner, Demick, \& Redondo, 1990). Thus, there are self-expressive, emotionally reassuring, and socially bonding ways of relating to personal possessions that have a positive impact on well-being. In contrast to MVO, these beneficial orientations often entail objects that have little material value.

\section{Theoretical Explanations of the Link between MVO and Well-Being}

MVO is a particular value or life goal that has to be understood in the context of Value Theory (Rokeach, 1973). The original definition of a value as "an enduring belief that a specific mode of conduct or end state of existence is personally or socially preferable to an opposite or converse mode of conduct or end state of existence" (p. 5) remains pertinent, and subsequent developments have shown convincingly that values worldwide can be summarized as arranged in a circumplex, with two main axes. Seminal work by Schwartz and colleagues identified ten value types, where values located next to each other on the circle are similar, whereas dissimilar values are located opposite (Schwartz, 1992). The two perpendicular axes represent value types that 
Error! No text of specified style in document. The Impact of a Materialistic Value Orientation on Well-Being

range from Self-Enhancement to Self-Transcendence, and from Conservation to Openness to Experience. Most similar to MVO are power, wealth, and achievement, which are self-enhancing values. These are the opposite of helpfulness, equality, and social justice, representing selftranscendent values. Later work using the life-goal measure described earlier, showed that the MVO values of money, fame, and image are extrinsic and opposite to community and affiliation values (Grouzet et al., 2005). What is important about placing MVO in the context of other values is, first, evidence showing that opposite values are linked in the sense that the more a person endorses one of them, the less the person endorses the opposite value (Maio, 2015) and that experimental priming of a value "crowds out" or reduces the opposite value (Maio, Pakizeh, Cheung, \& Rees, 2009). Second, a large body of evidence supports the proposal that some values are good for well-being and some values are bad.

Much of that evidence arises from one of the most important theoretical frameworks for understanding the link of values or goals with psychological well-being: Self-Determination Theory (SDT), developed by Ryan and Deci in the 1990s. This highly influential account, which was central to the development of the Positive Psychology movement, holds that there are three universal, basic human needs that need to be fulfilled for well-being to develop: agency (a sense of free will rather than coercion), competence (a sense of efficacy and mastery), and relatedness (a sense of close relationships with others). Self-transcendent, rather than self-enhancing, values and goals are conducive to fulfilling these needs, thus leading to higher well-being. It is assumed that self-enhancing values are linked with extrinsic motivation, which is characterized by a concern with sanctions from others (rewards or punishments) and a sense of having to fulfill standards that others have chosen or imposed. In contrast, intrinsic motivation refers to being guided by standards that people have freely chosen for themselves (yan \& Deci, 2000). MVO 
Error! No text of specified style in document. The Impact of a Materialistic Value Orientation on Well-Being

involves both self-enhancing goals and extrinsic motivation, and thus is likely to be doubly detrimental to the fulfillment of basic psychological needs.

Work on MVO within a self-determination framework has flourished since the early 1990, starting with a seminal paper on the "dark side of the American dream", showing that strong MVO is linked to less vitality, lower psychological functioning, and stronger symptoms of anxiety (Kasser \& Ryan, 1993). Furthermore, MVO is stronger when people grow up in environments that lack nurturance, such as "broken” family homes (Rindfleisch, Burroughs, \& Denton, 1997) or, more generally, socio-economic or non-loving familial backgrounds that are less supportive of children's growth, self-expression, and intrinsic needs (Kasser, Ryan, Zax, \& $\underline{\text { Sameroff, 1995). Kasser has developed this work into a framework that sees psychological }}$ insecurity as a major mechanism that leads individuals to adopt MVO as a coping strategy—one that is culturally sanctioned, but maladaptive (Kasser, 2002, 2016). In a similar vein, a recent systematic review conceptualized buying goods to blunt negative feelings as a materialistic escape from the self (Donnelly, Ksendzova, Howell, Vohs, \& Baumeister, 2016). Several experimental studies show that inducing people to feel psychologically insecure leads directly and immediately to a stronger endorsement of MVO and related consumer behaviors (Arndt, Solomon, Kasser, \& Sheldon, 2004; Kasser \& Sheldon, 2000; Sheldon \& Kasser, 2008). Kasser argues that MVO is aligned with the values and profit motive central to free market, capitalist economic systems (Kasser, Cohn, Kanner, \& Ryan, 2007). This argument is supported by research showing that culture-level indices of threat, instability, and advertising spend between 1976 and 2007 were linked with changes in MVO in a large sample of over 350,000 US adolescents (Twenge \& Kasser, 2013). Societal instability and disconnection (unemployment, divorce) and spending on advertising, which profiles materialistic concerns, had associations 
Error! No text of specified style in document. The Impact of a Materialistic Value Orientation on Well-Being

with higher levels of MVO, both contemporaneously and over time. The importance of money and of owning expensive material goods increased, peaking in the late 1980s to early 1990s with Generation X (born between the early 1960s and late 1970s) and then staying at high levels for Millennials (born between the early 1980s and late 1990s).

MVO is strongly profiled in the culture of mass consumer societies, particularly in fashion and in advertising. An excellent example is an advert by a UK retail chain screened around Christmas 2011, where rapping kids show each other that they need expensive branded consumer goods to be cool and liked by their peers and tell their parents that they need to buy these goods if they want to be a "lovely, lovely mother"; loan facilities are offered at the same time (www.youtube.com/watch?v=qGIN_SbjtYA). This advert resulted in a large number of complaints to the UK's Advertising Standards Authority (Sweney, 2011), but its contents were not judged to breach any advertising code.

The link between national advertising spending and the strength of cultural-level materialistic values (Kasser, 2011) supports the proposal that advertising is a potent source of materialistic images and messages that become internalized through frequently being exposed to them. At the level of individual socialization, greater media exposure in children is linked to stronger MVO (Opree, Buijzen, \& Valkenburg, 2012). Similarly, Dittmar (2018) argues that the consumer culture ideal of materialistic striving has a powerful psychological impact in mass consumer societies. Celebrities, fashion models, media stars, even computer game heroes and toys, influence who young people aspire to be. Having the "right" branded and expensive, consumer goods and an affluent lifestyle has become vital, not so much because of these material goods themselves, but because of hoped-for psychological and social benefits: greater popularity, a more positive sense of identity, social status, and greater happiness. The prominence accorded 
Error! No text of specified style in document. The Impact of a Materialistic Value Orientation on Well-Being

to the material "good life" as a goal we should strive for is central to MVO, as is the belief that an affluent lifestyle has a transformative power, offering a golden bridge to better self-identity, social status, and greater well-being.

The Consumer Culture Value Impact Model (Dittmar, Banerjee, Easterbrook, Hurst, \& Wright, 2017, see Figure 15.1) conceptualizes MVO as consisting of materialistic motives and materialistic value internalization (Banerjee \& Dittmar, 2008). An example of a materialistic motive is the belief that having money and expensive possessions is important "because others like you more". "I wish I was rich like the celebrities on $T V$ " is an example of a materialistic value item that has been internalized as a personal long-term goal (Easterbrook et al., 2014).

\section{[Insert Figure 15.1 Here]}

Figure 15.1 The Consumer Culture Value Impact Model of a Materialistic Value (MVO) and an Ideal Body Orientation ${ }^{1}$ (IBO) as Predictors of Identity Deficits and Well-Being

MVO leads us to be particularly attentive to materialistic ideals in the media, and when we compare ourselves to unrealistic standards of affluence and owning expensive consumer goods, we typically experience a discrepancy between who we would like to be - a person like the materialistic model we are confronted with — and who we actually are. Such selfdiscrepancies are harmful self-appraisals linked to negative emotions, such as dejection, gloom, and depression (Higgins, 1987; Dittmar, 2007, 2008, 2011). Such self-discrepancy states-a combination of negative self-appraisal and negative emotions — are psychologically painful, and we are motivated to escape them. Here the prominent consumer culture message of retail therapy offers a culturally sanctioned coping strategy: It advocates that the consumption of desirable goods, and the activity of shopping itself, are effective strategies for alleviating such negative 
Error! No text of specified style in document. The Impact of a Materialistic Value Orientation on Well-Being

self states. Yet, the behaviors that result may be the exact opposite: Overspending and excessive buying of goods are behavioral manifestations of maladaptive coping strategies that may lead to a brief "high" but are harmful in the longer term to people's personal well-being, leading to negative emotions, negative self-appraisal, and mental health problems. They are also detrimental to ecological well-being because they lead to high rates of consuming and waste. The frameworks discussed so far clearly predict that MVO is toxic for well-being.

Some perspectives, however, propose that MVO can, or should, have positive effects on well-being, at least in certain contexts. From a free market economic perspective, MVO is viewed as a motivational driver for individual effort and achievement, as well as a motor for economic growth, and is thus beneficial for both individuals and countries:

Our enormously productive economy demands that we make consumption our way of life, that we convert the buying and use of goods into rituals, that we seek our spiritual satisfaction and our ego satisfaction in consumption. We need things consumed, burned up, worn out, replaced and discarded at an ever-increasing rate.

(Lebow, 1955)

The wealth of both nations and individuals may be a major moderating influence, but in opposite directions. On the one hand, MVO may be good (or at least not bad) for the wealthy because they have better opportunities to fulfill their materialistic desires than do the poor. On the other hand, MVO may have beneficial effects for the poor because it encourages them to strive more for fulfillment of their basic material needs (see Dittmar et al., 2014, for more detail). The personenvironment congruence hypothesis states that people derive positive well-being from their values if they are in an environment that explicitly supports those values, which implies that 
Error! No text of specified style in document. The Impact of a Materialistic Value Orientation on Well-Being

MVO would be good for individuals who work or study in MVO-supportive environments, such as business, marketing, or economics, or who live in societies that are particularly high in MVO as a cultural value (Kasser \& Ahuvia, 2002; Sagiv \& Schwartz, 2000).

\section{Research on the Link Between MVO and Well-Being}

In addition to the diverse sets of single studies that show negative correlates of MVO, metaanalyses provide powerful evidence for the link between MVO and well-being because they assess and evaluate the strength of this link by (a) synthesizing across all available research studies that contain relevant measures, (b) testing whether the strength of the link is influenced by various factors (moderators), and (c) testing mechanisms that have been proposed to explain the link (mediators).

\section{MVO and Personal Well-Being}

A wide-ranging meta-analysis focused on the link between MVO and personal well-being examined four different dimensions of well-being (Dittmar et al., 2014): subjective well-being, self-appraisals, psychiatric symptoms and compulsive buying, and physical health. Subjective well-being (SWB) is a person's evaluation of his or her quality of life over time, as well as his or her experience of positive rather than negative emotions. High SWB indicates that one is satisfied with one's life and feels happy more frequently than unhappy (Diener, Suh, Lucas, \& Smith, 1999; see also Chapter 1). Self-appraisals are people's evaluations of themselves, which can be positive, such as self-esteem, or negative, such as self-doubt. Symptoms of depression and anxiety, as well as compulsive buying, are indicators of mood-related mental health problems as 
Error! No text of specified style in document. The Impact of a Materialistic Value Orientation on Well-Being

found in the Diagnostic and Statistical Manual of Mental Disorders of the American Psychiatric Association (DSM-IV-TR, 2000). The final category of well-being was physical health: somatic symptoms of ill health and risk behaviors, such as alcohol or drug addiction.

Synthesizing findings from over 250 studies, the core finding of the meta-analysis was a robust and significant link between higher MVO and lower personal well-being.

\section{[Insert Figure 15.2 Here]}

Figure 15.2. Effect Sizes of the Link Between MVO and Dimensions of Personal Well-Being

As shown in Figure 15.2, the strength of this link differs depending on the particular dimension of personal well-being examined, but the most striking finding is that all effect sizes are negative and statistically reliable. The valence of negative well-being dimensions was reversed, such that the negative sign of the effect means a worse well-being outcome, for instance, that higher MVO is linked to more negative affect. The effect sizes range from .13 for life satisfaction, a small effect, to .44 for compulsive buying, which indicates a large effect.

This core finding documents the weight of the evidence in this entire field of research. However, a meta-analysis can also address further research questions. The meta-analysis examined a range of factors that may influence the strength of the link (moderators) and concluded that the core finding is robust. Most factors tested were not a significant influence on the strength of the link between MVO and personal well-being, often challenging predictions made in the literature, including those made about cultural values, economic systems, and national or individual wealth. In the few instances where the strength of the link differed significantly by moderator, only the size of the link varied, not the direction: Higher levels of MVO were always linked to lower well-being. For example, consistent with the person- 
Error! No text of specified style in document. The Impact of a Materialistic Value Orientation on Well-Being

environment congruence hypothesis, the larger the proportion of the sample studying or working in an environment likely to support MVO (e.g., business students, marketing managers), the weaker the link between individuals' MVO and lower personal well-being, with $r=-.19$ if none of the sample worked in such an environment and $r=-.12$ if the whole sample did. One cultural value moderated the effect, affective autonomy, such that correlations were stronger in nations high on the pursuit of pleasure and an exciting life (e.g., Denmark, $r=-.21)$ than in countries which score low on affective autonomy (e.g., Egypt, $r=-.09)$. Income and socio-economic status (SES) did not emerge as a significant moderator of the link between MVO and personal well-being. However, few studies reported income or SES data, limiting the robustness of this finding.

Finally, the meta-analysis examined underlying processes proposed to explain this negative link (see section above on theoretical explanations), even though the number of studies in the meta-regression was relatively small. Higher MVO was linked to lower satisfaction of basic needs that, in turn, was linked to lower personal well-being, supporting SDT. In addition, MVO was linked to stronger extrinsic motives, which are linked to lower well-being. This finding is consistent with the three theoretical perspectives on MVO discussed earlier.

This meta-analysis also revealed a number of research gaps, including few studies with longitudinal and experimental designs, and few studies involving children. To address the dearth of research linking MVO with young children's well-being, the Children's Consumer Culture Project, which included over 2,000 children in the UK, examined a number of dimensions of well-being: symptoms of depression, subjective well-being, and symptoms of physical ill health. Among a sample of over 500 7- to 11-year-olds, greater endorsement of materialistic motives and materialistic values were significant predictors of lower well-being (Dittmar et al., 2017). 
Error! No text of specified style in document. The Impact of a Materialistic Value Orientation on Well-Being

The strength of the link was slightly lower than that reported as the average in the meta-analysis with predominantly adult samples but is still statistically reliable already in such young children.

Relationships between MVO and well-being were modeled over three time points.

Children's initial well-being and endorsement of MVO were modeled as predictors of each other 8 months later; well-being and MVO from this time point were then modeled to predict one another after a further 8 months (16 months after the start of the project). The resulting model shows a pattern whereby (a) initial MVO significantly predicts lower well-being 8 months later and (b) lower well-being at time 2 is linked significantly with a stronger endorsement of MVO 8 months later. These results suggest a vicious cycle whereby MVO initiates a deterioration of well-being during the following 8 months that, in turn, then leads children to an increased adoption of MVO as a personal goal. These findings are consistent with all three theoretical perspectives outlined in section 2 and support the causal emphasis in the Consumer Culture Value Impact Model and Self-Determination Theory by suggesting that the endorsement of MVO may well be the causal starting point for negative changes in young children's well-being.

Good examples of some of the longitudinal research with adolescents and adults, are several studies reported in a single article (Kasser et al., 2014) that show that adolescents with higher MVO suffered impaired social and psychological functioning 20 years later and that wellbeing in Iceland, after its economic crash in 2008, increased over time when MVO decreased. This work can go some, but not all, the way towards addressing the question of antecedence, which is a necessary pre-condition for causality.

To address the question of causal direction directly, we need experimental studies. An intervention with groups of adolescents in the US and their parents showed that focusing on less materialistic orientations towards money and material goods, such as saving, led to a reduction in 
Error! No text of specified style in document. The Impact of a Materialistic Value Orientation on Well-Being

MVO among the adolescents who were initially high in MVO (Study 4 in Kasser et al., 2014).

For adults, the sparse experimental evidence supports a bi-directional relationship. Priming MVO led to an immediate reduction in well-being (Bauer, Wilkie, Kim, \& Bodenhausen, 2012), and experimental manipulations of psychological insecurity showed that such insecurity leads to an increased endorsement of MVO and related behaviors, such as higher consumption (Sheldon $\underline{\text { \& Kasser, 2008). }}$

\section{MVO and Social Well-Being}

A search for personal characteristics likely to impact social well-being that are associated with MVO yields a long list of problematic personality traits, relationship difficulties, anti-social attitudes, and socially harmful behaviors. MVO is higher in people who suffer from psychopathy, Machiavellian, and narcissistic personality disorders (Pilch \& Durnik-Durose, 2016), all known to be linked with anti-social or aggressive behaviors. Individuals high in MVO report less satisfaction with their close relationships (Carroll, Dean, Call, \& Busby, 2011); hold stronger prejudices against a range of ethnic and racial groups (Duriez, Vansteenkiste, Soenens, \& De Witte, 2006); are less likely to be involved in community or charitable activities (Roberts

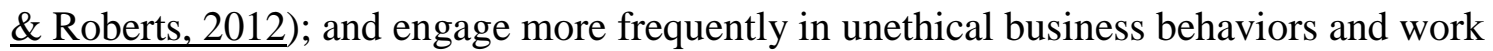
practices ( $\underline{\mathrm{Lu} \& \mathrm{Lu}, 2010})$.

One of the most striking features of contemporary consumer culture is that messages about what is "cool" are deliberately targeted at young children, thus making materialistic norms a significant focus of their socialization experience. Yet, MVO in children younger than 10 years had hardly been explored before the Children's Consumer Culture Project, which examined children age 7 to 14 years, even though parental worry about kids being damaged by materialism 
Error! No text of specified style in document. The Impact of a Materialistic Value Orientation on Well-Being

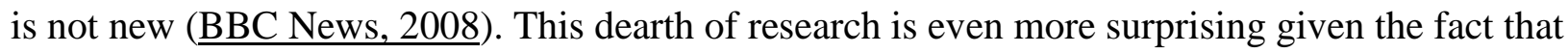
they are at a developmental stage where concerns with peer relations are strong and owning "cool things" comes to play a core role in social comparisons, self-presentation, and peer-group acceptance. Norms within their peer culture are very important to children in primary school, aged 7-11 years, a time when peer-group acceptance becomes a dominant social goal (Parker \& Gottman, 1989). Material goods and the beliefs associated with them have increasingly become a focus of peer-group interests and activities, as preadolescent children are a market segment that is heavily targeted by advertisers for a range of consumer goods-clothes, accessories, shoes, toys, mobile phones, and electronic items. As a consequence, children see materialistic norms as relevant to peer-group acceptance, and children feel pressured to fit in by adopting this material peer culture.

The first research linking MVO to young children's peer relations developed a new measure of perceived peer culture pressures in 7-11-year-olds and found that material characteristics form an integral part of peer culture, such as feeling under pressure to dress in

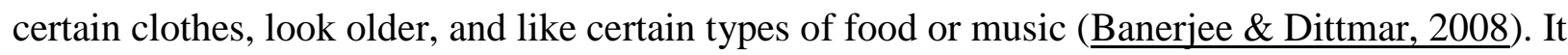
proposed that beliefs and cultural messages associated with "cool stuff" would generate particular social and extrinsic motives in children, such as wanting fashionable goods because “children like you more if you have 'cool' things". Furthermore, it was expected that children who have troubled relationships with their peers would be most likely to feel under pressure to conform to the surrounding peer material culture and would endorse extrinsic social motives for wanting "cool" things, which, in turn, would predict the extent to which they internalize MVO. The key findings from two surveys support these proposed links: Children rejected by their peers (i.e., most nominated by their classmates as somebody they would "least like to play with") 
Error! No text of specified style in document. The Impact of a Materialistic Value Orientation on Well-Being

reported stronger perceptions of peer culture pressure, which were associated with stronger extrinsic social motives for wanting "cool" things. These materialistic motives were closely linked with MVO.

The Children's Consumer Culture Project subsequently examined what characteristics of a child predict peer acceptance over time (Banerjee, Dittmar, Easterbrook, Hurst, \& Wright, 2017). Sociometric data from children offer an objective (as opposed to self-reported) assessment of peer relations. To measure differences among children in the extent to which they are liked by their peers, sociometric procedures typically require all children in a class to nominate three peers with whom they "most like to play" and "least like to play" (Coie, Dodge, $\underline{\text { \& Coppotelli, 1982) }}$. Rejected children are those who receive few "most like to play" nominations and many "least like to play" nominations. The project assessed additional characteristics of children, using an adapted sociometric method. First, children were asked to nominate three peers in their class who are most "cooperative" and most "disruptive", because these characteristics have been identified as strong predictors of peer liking (Mostow, Izard, Fine, \& Trentacosta, 2002). Second, it assessed characteristics specific to consumer culture by asking children to nominate three peers who have the most "cool stuff" and the best "good looks". Finally, we asked children to nominate three classmates who are seen as most "popular" in the class.

The existing research illuminates the important distinction between levels of acceptance based on actual liking by group members and levels of perceived popularity (Parkhurst \& Hopmeyer, 1998; La Fontana \& Cillessen, 1999). Although these appear similar (popularity after all should mean being well liked), research indicates substantial divergence: Those who are perceived to be popular often exhibit a behavioral profile of social dominance that contrasts with 
Error! No text of specified style in document. The Impact of a Materialistic Value Orientation on Well-Being

the more affiliative, prosocial, and cooperative behavior of those who are actually well liked (La Fontana \& Cillessen, 2002; Lease, Musgrove, \& Axelrod, 2002).

We hypothesized that "cool stuff" and "good looks" would be associated with the perception of social status - perceived popularity_more than with actual liking. Modeling of sociometric and self-report data from over 2,000 children over 3 school years revealed crosslagged associations that show that cooperative behavior was a positive predictor of subsequent liking by peers, whereas a reputation for having the most stuff and looking good—along with disruptive behavior - predicted gains in being perceived as popular. Thus, in contrast to children's strong beliefs that "children like you more when you have 'cool' things", the MVOrelated characteristics of having the most stuff and looking good were unrelated to actual peer acceptance. Moreover, we found that early peer rejection predicted an increase over time in extrinsic (social status) motivations for pursuing consumer culture ideals. This, in turn, predicted worsening, rather than improving, peer relations. Our results highlight the misconceived and potentially damaging assumption that pursuing consumer culture ideals such as MVO would lead to social "success". Instead, they suggest a vicious cycle in which peer rejection is linked with counterproductive motivations to increase social peer status though MVO. It also demonstrates that the images of social success heavily promoted by consumer culture are social representations of popularity, but do not lead to actual peer acceptance, and maybe have damaging effects on the motivational orientation of children who are experiencing difficulties in their peer relations.

\section{MVO and Consumer Well-Being}


Error! No text of specified style in document. The Impact of a Materialistic Value Orientation on Well-Being

Overspending and excessive buying of goods are often maladaptive coping strategies that may lead to a brief "high" but are harmful in the longer term. MVO has been identified as a significant predictor of consumer debt (Watson, 2003; Garðarsdottir \& Dittmar, 2012).

Excessive buying of consumer goods central to compulsive buying is included in the current Diagnostic and Statistical Manual (DSM-V; APA, 2015) under the category of "behavioral addictions", that is, addictions where no substance is consumed (such as drugs or alcohol). Although there is not yet a consensus on the precise definition of compulsive buying, there is agreement on three characteristics: preoccupation with shopping and buying, irresistible impulses to buy as soon as a person sees consumer goods, and continuing with buying despite harmful consequences. A possible fourth characteristic is a search for a better self-identity (see Dittmar, 2004, 2008; Dittmar \& Bond, 2010).

Questionnaire surveys on buying in shops and buying online (Dittmar, 2005a, 2005b; Dittmar, Long, \& Bond, 2007) and interviews with self-diagnosed compulsive buyers (Dittmar, 2004, Dittmar \& Drury, 2000) have revealed that higher MVO is linked to stronger tendencies towards attitudes and behaviors characteristic of compulsive buying. Such compulsive buying tendencies are a gradated continuum with compulsive buying at a clinical level at the extreme upper end. MVO is linked compulsive buying tendencies through motivations for buying that are focused on repairing and improving self-identity, mood, and emotions. There is also substantive evidence that compulsive buying is associated with lower personal well-being; higher mental health problems; such as depression and anxiety, and co-morbidity with impulsive-compulsive psychiatric disorders (Black, 2006; Dittmar, 2004; Maraz, Griffiths, \& Demetrovics, 2016). There is also evidence that compulsive buying tendencies are increasing in developed mass consumer societies (Neuner, Raab, \& Reisch, 2005), which is reflected in age cohort prevalence 
Error! No text of specified style in document. The Impact of a Materialistic Value Orientation on Well-Being

figures: Younger consumers report stronger compulsive buying tendencies than older consumers. These tendencies were shown to be due to stronger MVO in a UK study comparing samples of younger and older consumers (Dittmar, 2005b). In the meta-analysis reported earlier, the link between MVO and compulsive buying was the strongest effect found.

We also carried out an experimental study to examine whether exposure to a materialistic role model would have direct and immediate effects on children's behavior (Dittmar, Banerjee et

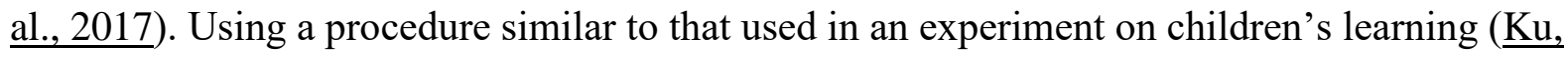
Dittmar, \& Banerjee, 2014), we showed 8-10-year-olds a "video diary" of a same-sex child talking excitedly about Christmas. In the extrinsic materialistic prime, the child in the video talked about getting lots of expensive presents, which would make other children envious, although they would still want to play with the owner of those presents. In the intrinsic prime, the child talked about having lots of quality time with friends and family, where they would have fun and enjoy each other's company. A neutral video in which children watched abstract moving shapes (control condition) primed no values at all. As a measure of rudimentary consumer behavior, we gave children photocopied money notes totaling $£ 100$ and asked them to distribute this windfall money between three different activities: spending on self, spending on others, and saving. Then, we asked them whether they would like to borrow further money, making it clear that, this time, this would be money that they would need to pay back. Children's borrowing decisions in this task can be seen as a rudimentary consumer behavior that indicates spending money that one does not have- that is, going into debt.

The type of video the children saw had a direct impact on their materialistic motives, which were highest after the extrinsic materialistic video and lowest after the intrinsic video emphasizing close relationships with friends and family; means after the neutral video were in 
Error! No text of specified style in document. The Impact of a Materialistic Value Orientation on Well-Being

between. Crucially, the type of video also had a strong effect on how much money the children wanted to borrow. In the neutral video condition, the average amount of money children wanted to borrow just over $£ 8$, and just below $£ 8$ in the intrinsic value condition. In contrast, children wanted to borrow over $£ 17$ after having been exposed to materialistic modeling by a peer. Such materialistic peer modeling mirrors closely the advertising typically aimed at children of this age group.

\section{MVO and Environmental Well-Being}

MVO appears to be detrimental, not only to individual and interpersonal well-being, but to environmental well-being as well. Many studies have linked the pursuit of economic growth to the erosion of the natural environment, at a global level (e.g., Jackson, 2009): Internationally, the pursuit of economic growth is argued to take a toll on the environment. At a country level, these suggestions appear to hold true: The more citizens of a country endorse MVO, or closely related values from Schwartz's circumplex, such as power and hierarchy, the higher the level of that country's carbon dioxide emissions (Kasser, 2011).

At the level of the individual, considerable cross-sectional research links greater endorsement of MVO to lower environmental concern and more damaging environmental behavior. A comprehensive review of the literature and meta-analysis of 13 independent samples showed that MVO was associated significantly with both lower pro-environmental attitudes $(\hat{\rho}=$ $-.28)$ and environmental behaviors $(\hat{\imath}=-.32)$, representing medium effect sizes (Hurst, Dittmar, Bond, \& Kasser, 2013). These links were not moderated by age or gender. However, a number of questions remain that this research cannot answer, which are explored below. 
Error! No text of specified style in document. The Impact of a Materialistic Value Orientation on Well-Being

\section{Why Are MVO and the Environment Linked?}

One possible explanation for the link between MVO and environmental attitudes and behaviors draws on theoretical work described earlier, relating to value conflict or value opposition.

Materialistic values tend to be closely associated with self-enhancement values and are thus inconsistent with self-transcendence values, which focus on benevolence and universalism.

Universalism is particularly relevant for environmental concerns as it implies a consideration and value for both protecting the natural environment, as well as equality and fairness among humans (Schwartz, 2012). However, materialistic values' negative association with further other-oriented values, such as benevolence, may also lead to detrimental environmental behaviors. Indeed, some have conceptualized environmental crises as social dilemmas (ㅂardin, 1968), and research from this perspective provides further support that prosocial behaviors (e.g., those intended to benefit others) and pro-environmental behavior and attitudes are linked (e.g., Kaiser \& Byrka, 2011; Van Lange, 1999). If materialistic values suppress prosocial values, they are likely to also suppress pro-environmental values. However, beyond this shared explanation with influences on personal well-being, there are also a number of explanations for the association between a materialistic value orientation and environmental attitudes and behaviors which are specific to these outcomes.

Materialistic values may also be associated with particular worldviews that are detrimental to the environment. Kasser (2002; Khanna \& Kasser, 2001) provides evidence that materialists are more likely to objectify other human beings, viewing them as a means to an end, and this appears to extend to the natural world. Individuals who more strongly believe that money is important in their lives have more instrumental views of nature and are more likely to 
Error! No text of specified style in document. The Impact of a Materialistic Value Orientation on Well-Being

believe that nature exists to be exploited by humanity (Hedlund-de Witt, de Boer, \& Boersema, 2014). These anthropocentric views of the environment are typically associated with less environmentally friendly attitudes and behaviors, such as higher emission transport choices and lower levels of recycling (e.g., De Groot \& Steg, 2007). Thus, to the extent that MVO promotes this anthropocentric orientation towards the environment, it may also promote other negative environmental attitudes and behaviors.

The two processes above, of value conflict and anthropocentric worldviews, focus primarily on MVO as an indirect influence on environmentalism: MVO is related to environmental behavior via environmental attitudes. However, Brown and Kasser (2005) suggest that MVO has a more direct influence on environmental behavior via its influence on consumer behavior. People higher in MVO are more concerned with material possessions and demonstrating status via these, suggesting that they are likely to consume more, and thus have larger ecological footprints, by using more resources and generating more waste. The findings of

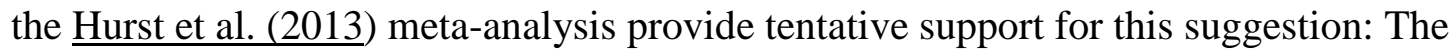
correlations between MVO and environmental behaviors and attitudes were similar in size, suggesting there are influences of MVO on environmental behaviors which are not dependent on its association with attitudes. Future research could consider this link with environmental behavior more specifically by focusing on particular behaviors. Brown and Kasser (2005) suggest that people high in MVO are directly harmful to the environment because they consume more luxury goods, drive more "impressive" but fuel-intense cars, and purchase larger homes. However, a recent analysis of Swedish participants' actual emissions (estimated from objective sources, e.g., energy bills) suggests that this is not the case (Andersson \& Nässén, 2016). More materialistic participants were responsible for greater greenhouse gas emissions, but this was due 
Error! No text of specified style in document. The Impact of a Materialistic Value Orientation on Well-Being

primarily to their greater use of air travel. Understanding the particular behaviors people higher in MVO are more likely to engage in may help in designing interventions to combat MVO's negative effects.

A final possibility is that those who are higher in MVO live more in the present: They seem to value the future less than those who are not so driven by money and status. Environmental behavior is, to an extent, an issue of time perspectives: Environmentally damaging behaviors (such as air travel or the consumption of luxury goods) offer immediate rewards in the present, whereas their environmental impact is only visible at a later time. Interestingly, research suggests participants do not sufficiently consider the temporal elements of environmental dilemmas (Messick \& McClelland, 1983). Thus, if higher MVO makes individuals focus more on the present, and less likely to adopt a future time perspective in general, then they may be even less likely to engage in pro-environmental behaviors. There is some tentative evidence that those higher in MVO focus even more on the present at the expense of the future than those low in MVO: In a hypothetical consumer situation, where participants gained goods of higher value if they waited longer before receiving them, participants who were higher in MVO required considerably higher values of goods later to consider the delay worthwhile (Dittmar \& Bond, 2010). Time perspectives (present and future) also appear to play a critical role in determining MVO's effects on problematic spending behaviors, where a focus on future time perspectives mitigates some of the negative effects of MVO on problematic spending behaviors ( $\underline{\mathrm{Ku}, \mathrm{Wu}, \mathrm{LaO}, \& \mathrm{Lam}, 2016})$. Thus the link between MVO and time perspectives may be worth investigating further because it may be a potential intervention target for reducing MVO's impact on the environment. 
Error! No text of specified style in document. The Impact of a Materialistic Value Orientation on Well-Being

Clearly there are many ways that MVO may be associated with pro-environmental behaviors and attitudes. These processes are not mutually exclusive; indeed, a number of these processes may be acting simultaneously, and future research should explore how they are interlinked.

\section{Cause or Effect?}

A second question that the cross-sectional literature cannot address concerns the direction of the link between MVO and environmental outcomes, including whether this link is causal. However, longitudinal research can examine this question, by assessing whether MVO predicts decreases in pro-environmental behavior over time, or vice versa. In a 2-year longitudinal study with participants in the UK and Chile, Unanue, Vignoles, Dittmar, \& Vansteenkiste (2016) found a significant effect of MVO on environmental behavior over time: The more materialistic participants were, the more environmentally damaging their behavior was at the next follow-up, even when controlling for their initial levels of environmental behavior.

Additional support for a causal influence of MVO on environmentalism can be found in the gradually expanding number of experimental studies. Participants primed with intrinsic values recommended smaller ecological footprints for policy targets (specifically the use of public transport, reduced air travel, and reduced home size) and donated more imaginary earnings from an experimental game to an environmental fund or cause (Ku \& Zaroff, 2014; Sheldon, Nichols, \& Kasser, 2011). In other research, participants who were exposed to images of natural environments and imagined the experience of being in these reported higher levels of intrinsic (and lower levels of extrinsic) values, compared with participants who were exposed to industrial and urban images (Weinstein, Przybylski, \& Ryan, 2009). This suggests that the causal 
Error! No text of specified style in document. The Impact of a Materialistic Value Orientation on Well-Being

influences may run in both directions, rather than simply one. Future research should seek to extend these findings beyond single experimental manipulations and develop interventions based around their principles to further confirm the causal directions suggested here. Such interventions could examine the principles of value priming on a longer-term basis than an individual experiment but could also investigate the effect on values of engagement with nature in a real-world context.

\section{Within- and Between-Country Sampling}

The majority of the research relating MVO and environmental attitudes and behaviors comes from samples that are restricted in two key ways. First, there is relatively little variation in the socio-economic status of the samples within countries. For this reason, we can only say that MVO is negatively associated with environmental attitudes and behaviors among relatively affluent, well-educated people. Second, the majority of the samples in the Hurst et al. (2013) meta-analysis come from developed Western countries, and research in other countries has produced mixed findings. Some research suggests that the same negative associations emerge in correlational and longitudinal studies in non-Western and less developed countries (Hong Kong,

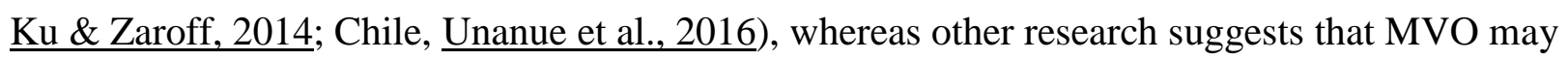
be less strongly associated with negative environmental attitudes and behaviors outside of developed Western countries (e.g., in developing economies like China, Gatersleben, Jackson, Meadows, Soto, \& Yan, 2012) or that its effects may be moderated by factors relating to globalization (e.g., the extent to which individuals see themselves as a citizen of the world, Strizhakova \& Coulter, 2013). Andersson and Nässén (2016) argue that materialistic values may be expressed differently in different cultures and will therefore be associated with different 
Error! No text of specified style in document. The Impact of a Materialistic Value Orientation on Well-Being

behaviors and attitudes across these cultures. Examining these cross-cultural differences in expression may be a fruitful line of research.

\section{What Can We Do to Understand MVO Better and Reduce It?}

The limitations of studies on the link between MVO and well-being identified in this chapter set a future research agenda. There is need for integrated longitudinal and experimental research to offer a more detailed understanding of the causal direction between MVO and lower well-being and to investigate in greater depth the underlying processes that mediate the links. Progress may come through the systematic use of multi-method approaches, possibly supported by field experiments and observational studies. This could be further supported through the use of nonreactive measures, such as experience sampling and actual behaviors, in addition to self-report scales and quasi-behavioral measures that tend to focus on hypothetical scenarios. In addition, research could investigate promising strategies for changing values and behaviors.

Because of the power of consumer goods advertising, reducing MVO is like David fighting Goliath. We should not, however, underestimate the power of well-constructed interventions based on sound psychological theory and research. Strategies for change can range from encouraging individual's critical reflection on the contents and aims of media representation of the "good life" and MVO as a value, to group-based interventions, and to local and national advertising policy. We need developments on all of these fronts. Policy change is typically the hardest to achieve, but lasting change is most likely when individual critical thinking extends to change in shared values as general guiding principles for our lives and our 
Error! No text of specified style in document. The Impact of a Materialistic Value Orientation on Well-Being

behavior and when, in turn, those changes are embedded in, and supported by, a wider context of policy change. Of course, policy change may also lead to changes in social values, so that there is a bi-directional interaction between change at an individual and at a social level.

\section{Critical Reflection on Materialistic Media Contents}

Effective treatment of adults suffering from compulsive buying typically includes examining, and critically reflecting on, materialistic modeling and messages in advertising (Benson, 2008; Www.stoppingovershopping.com). Advertising messages suggest strongly that buying and consuming material goods is a good strategy for achieving social and personal goals, as well as a successful coping strategy for feeling low and dissatisfied with ourselves (Dittmar, 2008). Coming to understand that these messages are not only untrue, but potentially damaging is effective in helping people resist their excessive buying habits (Benson, 2012, personal communication). Although there do not (yet) seem to be such critical thinking interventions designed specifically to reduce MVO, a large number of such interventions have attempted to reduce the impact of consumer culture ideals closely linked to MVO. These are appearancefocused ideals, such as a thin body for women and a muscular body for men, which lead to higher body dissatisfaction, a potent predictor of unhealthy body-related behaviors, such as disordered eating or taking muscle-enhancing substances (Cafri et al., 2005; Stice, 2002). One example is exposure to the Dove Evolution video (www.youtube.com/watch?v=iYhCn0jf46U), which shows the techniques used to create images of idealized women models, as an intervention to protect girls against the negative impact of body perfect models on their body image (Halliwell \& Diedrichs, 2014). Other interventions have been developed with the aim to reduce the internalization of body perfect ideals of extreme thinness for girls and women (see meta- 
Error! No text of specified style in document. The Impact of a Materialistic Value Orientation on Well-Being

analysis by Stice, 2002), a strong predictor of body dissatisfaction (Halliwell \& Dittmar, 2004; Hurst, Dittmar, Halliwell, \& Diedrichs, 2016).

\section{Interventions to Change Values and Behaviors}

In contrast to the lack of MVO-focused critical awareness interventions, there are some studies that have focused on altering materialistic values and related behaviors. Experimental studies that prime intrinsic values (over extrinsic values such as MVO) report increased proenvironmental attitudes or behaviors (e.g., Ku \& Zaroff, 2014; Sheldon et al., 2011). However, these have been short term, have been examined primarily in laboratory settings, and have measured imagined outcomes or "recommendations" rather than real behaviors. Interventions have been developed to reduce materialism in other contexts, such as addressing adolescents' spending behavior and personal well-being (e.g., Kasser et al., 2014). An educational video about MVO's negative effects on people and the planet developed by Kasser (www.youtube.com/watch? $\mathrm{v}=\mathrm{oGab} 38 \mathrm{pKscw}$ ) could provide an excellent intervention for reducing MVO and encouraging pro-environmentalism at the same time.

A recent school-based intervention with primary school children in the UK showed that a week of pro-environmental activities and education led, not only to greater environmental knowledge, but also to a significant reduction in the self-enhancing values that are closely linked to MVO (Zamanpour, Dittmar, Döring, Mendese, \& Hurst, 2017). We also have preliminary evidence that mindfulness is helpful not only in increasing personal well-being (Grossman, Niemann, Schmidt, \& Walach, 2004) but may also be effective in reducing MVO and associated dysfunctional consumer behaviors in young adults (Dittmar, Strauss et al., 2017). 
Error! No text of specified style in document. The Impact of a Materialistic Value Orientation on Well-Being

\section{Advertising Spending and Policy}

School-based interventions would be strengthened if they did not stand alone. Real, lasting change of values and value-relevant behaviors is much more likely when supported by public recognition of the need for such change, priority on political agendas, and concurrent policy changes at local and national levels. Yet, despite the substantial evidence of the harmful impacts of MVO, policy-makers and politicians do not yet seem to recognize the gravity of these problems. In contrast to MVO, the damaging effects of consumer culture ideals focusing on appearance are on the international policy agenda. Examples are legal changes in France, Spain, Italy, and Israel that enforce that female advertising or catwalk models need to have a body weight that is categorized as healthy by the World Health Organisation, i.e., a Body Mass Index of at least 18 (see Paxton, 2015, for a full review). In the UK, the Body Confidence campaign by the UK government has led to numerous policy changes

(www.gov.uk/government/publications/body-confidence-progress-report-2015), and the first act of London's new mayor Sadiq Khan was to ban advertising on London's public transport that uses ultra-thin women models (www.london.gov.uk/press-releases/mayoral/mayor-incrackdown-on-body-image-advertisements).

Yet, there are already some examples of policy changes that may be effective in reducing people's endorsement of MVO. For example, Sweden has introduced policies to restrict advertising to children (Olsen, 2007). Furthermore, given evidence that exposure to advertising increases children's MVO (Opree et al., 2012) and that nations' advertising spend predicts cultural prevalence of materialistic values (Kasser, 2011), it is possible that policies which limit advertising on billboards — such as in Grenoble and Sao Paolo—-may contribute towards lower 
Error! No text of specified style in document. The Impact of a Materialistic Value Orientation on Well-Being

levels of MVO. What is needed is the development of local and national advertising policies that explicitly aim to reduce MVO, and scientific evaluation of such interventions.

Interventions at both individual and social levels, as well as collaboration between parents, schools, practitioners in education and health, and policy-makers are crucial for alleviating MVO, a major source of lower well-being in contemporary consumer culture.

Irish philosopher and priest John O’Donohue offers this insightful synopsis:

Our consumerist culture thrives on the awakening and manipulation of desire. This is how advertising works. It stirs our desire and then cleverly directs it towards products. Advertising is the schooling of false desire and relies on our need to belong, to play a central part in society and not exist merely on the fringes of it. And because awakened desire is full of immediacy, it wants gratification and does not want to be slowed down or wait. It wants no distance to open between it and the object of desire: it wants to have it now. This manipulation of desire accounts for the saturation of our culture with products that we don't need but are made to feel we do. There is no end to false desire. Like the consumption of fast food, it merely deepens and extends the hunger. It satisfies nothing in the end.

(2014, pp. 43-44)

\section{Note}

\section{References}

American Psychiatric Association. (2000). Diagnostic and statistical manual of mental disorders (4th ed., text rev.). Washington, DC: Author.

American Psychiatric Association. (2013). Diagnostic and statistical manual of mental disorders (5th ed.). Washington, DC: Author. 
Error! No text of specified style in document. The Impact of a Materialistic Value Orientation on Well-Being

Andersson, D., \& Nässén, J. (2016). Should environmentalists be concerned about materialism?

An analysis of attitudes, behaviours and greenhouse gas emissions. Journal of Environmental Psychology, 48, 1-11.

Arndt, J., Solomon, M., Kasser, T., \& Sheldon, K. M. (2004). The urge to splurge: A Terror Management account of materialism and consumer behaviour. Journal of Consumer Psychology, 14(3), 198-212. doi: 10.1207/s15327663jcp1403_2

Banerjee, R., \& Dittmar, H. (2008). Individual differences in children's materialism: The role of peer relations. Personality and Social Psychology Bulletin, 34(1), 17-31. doi:

$10.1177 / 0146167207309196$

Banerjee, R., Dittmar, H., Easterbrook, M., Hurst, M., \& Wright, M. (2017). Good looks, cool stuff, and children's “popularity”: A cautionary tale. Child Development (Revise and resubmit).

Bauer, M. A., Wilkie, J. E. B., Kim, J. K., \& Bodenhausen, G. V. (2012). Cuing consumerism: Situational materialism undermines personal and social wellbeing. Psychological Science, 23, 517-523. doi: 10.1177/0956797611429579

BBC News. (2008). Children “damaged” by materialism. Last retrieved July 12, 2017 from http://news.bbc.co.uk/1/hi/uk/7262936.stm

Benson, A. (2008). To buy or not to buy: Why we overshop and how to stop. Boston, MA: Trumpeter Books.

Black, D. W. (2006). Compulsive shopping. In E. Hollander \& D. J. Stein (Eds.), Clinical manual of impulse-control disorders (pp. 203-228). Washington, DC: American Psychiatric Publishing. 
Error! No text of specified style in document. The Impact of a Materialistic Value Orientation on Well-Being

Brown, K., \& Kasser, T. (2005). Are psychological and ecological well-being compatible? The role of values, mindfulness, and lifestyle. Social Indicators Research, 74, 349-368. doi: $10.1007 / \mathrm{s} 11205-004-8207-8$

Cafri, G., Thompson, J. K., Riciardelli, M., McCabe, M., Smolak, L., \& Yesalis, C., (2005). Pursuit of the muscular ideal: Physical and psychological consequences and putative risk factors. Clinical Psychology Review, 25, $215-239$. doi:10.1016/j.cpr.2004.09.003

Carroll, J. S., Dean, L. R., Call, L., \& Busby, D. M. (2011). Materialism and marriage: Couple profiles of congruent and incongruent spouses. Journal of Couple and Relationship Therapy, 10(4), 287-308. doi: 10.1080/15332691.2011.613306

Coie, J. D., Dodge, K. A., \& Coppotelli, H. (1982). Dimensions and types of social status: A cross-age perspective. Developmental Psychology, 18, 557-570.

Cushman, P. (1990). Why the self is empty: Toward a historically situated psychology. American Psychologist, 45(5), 599-611.

De Groot, J. I. M., \& Steg, L. (2007). Value orientations and environmental beliefs in five countries: Validity of an instrument to measure egoistic, altruistic, and biospheric value orientations. Journal of Cross-Cultural Psychology, 38, 318-332. doi:

$10.1177 / 0022022107300278$

Diener, E., Suh, E. M., Lucas, R. E., \& Smith, H. L. (1999). Subjective well-being: Three decades of progress. Psychological Bulletin, 125, 276-302. doi: 10.1037/00332909.125.2.276

Dittmar, H. (1992). The social psychology of material possessions: To have is to be. Hemel Hempstead: Harvester Wheatsheaf. 
Error! No text of specified style in document. The Impact of a Materialistic Value Orientation on Well-Being

Dittmar, H. (2004). Understanding and diagnosing compulsive buying. In R. H. Coombs (Ed.), Handbook of addictive disorders: A practical guide to diagnosis and treatment (pp. 451494). New York: Wiley.

Dittmar, H. (2005a). A new look at "compulsive buying": Self-discrepancies and materialistic values as predictors of compulsive buying tendency. Journal of Social and Clinical Psychology, 24(6), 806-833. doi: 10.1521/jscp.2005.24.6.832

Dittmar, H. (2005b). Compulsive buying behaviour - a growing concern? An empirical exploration of the role of gender, age, and materialism. British Journal of Psychology, 96(4), 467-491. doi: 10.1348/000712605X53533

Dittmar, H. (2007). The costs of consumer culture and the "cage within": The impact of the material "good life" and "body perfect” ideals on individuals' identity and well-being. Psychological Inquiry, 18(1), 23-31. doi: 10.1080/10478400701389045

Dittmar, H. (2008). Consumer culture, identity and well-being: The search for the "good life" and the "body perfect". Hove, UK: Psychology Press.

Dittmar, H. (2011). Material and consumer identities. In S. J. Schwartz, K. Luyckx, \& V. L. Vignoles (Eds.), Handbook of identity theory and research: Domains and categories (pp. 745-769). New York: Springer.

Dittmar, H. (2018). Consumer society, identity, and well-being: The search for the "good life" and the "body perfect" (2nd rev. ed.). European Monographs in Social Psychology Series (edited by R. Brown). London \& New York: Psychology Press.

Dittmar, H., Banerjee, R., Easterbrook, M., Hurst, M., \& Wright, M. (2017). Is a materialistic value orientation detrimental to young children's well-being? Cross-sectional, 
Error! No text of specified style in document. The Impact of a Materialistic Value Orientation on Well-Being

longitudinal, and experimental evidence. Journal of Personality and Social Psychology, under editorial consideration.

Dittmar, H., \& Bond, R. (2010). I want it and I want it now: Self-discrepancies and materialistic values as predictors of ordinary and compulsive buyers' temporal discounting of different consumer goods. British Journal of Psychology, 101(4), 751-776. doi:

$10.1348 / 000712609 X 484658$

Dittmar, H., Bond, R., Hurst, M., \& Kasser, T. (2014). The relationship between materialism and personal well-being: A meta-analysis. Journal of Personality and Social Psychology, 107(5), 879-924. doi: 10.1037/a0037409

Dittmar, H., \& Drury, J. (2000). Self-image — is it in the bag? A qualitative comparison between ordinary and “excessive” consumers. Journal of Economic Psychology, 21(2), 109-142. doi: 10.1016/S0167-4870(99)00039-2

Dittmar, H., Long, K., \& Bond, R. (2007). When a better self is only a button click away: Associations between materialistic values, emotional and identity-related buying motives, and compulsive buying tendency online. Journal of Social and Clinical Psychology, 26(3), 334-361. doi: 10.1521/jscp.2007.26.3.334

Dittmar, H., Strauss, C., Cavanagh, K., Costin, V., Koc, Y., Marx, R., . . Yang, S. (2017). “I meditate, therefore I am, and I am well”: Consumer culture values, identity, mindfulness, and well-being. Manuscript in preparation for publication, University of Sussex.

Donnelly, G. E., Ksendzova, M., Howell, R. T., Vohs, K. D., \& Baumeister, R. F. (2016). Buying to blunt negative feelings: Materialistic escape from the self. Review of General Psychology, 20(3), 272-316. 
Error! No text of specified style in document. The Impact of a Materialistic Value Orientation on Well-Being

Duriez, B., Vansteenkiste, M., Soenens, B., \& De Witte, J. (2007). The social costs of extrinsic relative to intrinsic goal pursuits: Their relation with social dominance and racial and ethnic prejudice. Journal of Personality, 75(4), 757-782. doi: 10.1111/j.14676494.2007.00456.x

Easterbrook, M. J., Wright, M. L., Dittmar, H., \& Banerjee, R. (2014). Consumer culture ideals, extrinsic motivations, and well-being in children. European Journal of Social Psychology, 44(4), 349-359. doi: 10.1002/ejsp.2020

Garðarsdottir, R., \& Dittmar, H. (2012). The relationship of materialism to debt and financial well-being: The case of Iceland's perceived prosperity. Journal of Economic Psychology, $33,471-481$.

Gatersleben, B., Jackson, T., Meadows, J., Soto, E., \& Yan, Y. (2012). Materialism and environmentalism: Exploring the views of young adults in the UK, Spain and China. Unpublished manuscript. Guildford, UK: University of Surrey.

Goffman, E. (1961). Asylums. New York: Anchor.

Goffman, E. (1968). The inmate world. In C. Gordon \& K. J. Gergen (Eds.), The self in social interaction, vol. 1: Classic and contemporary perspectives (pp. 115-136). New York: Wiley.

Grossman, P., Niemann, L., Schmidt, S., \& Walach, H. (2004). Mindfulness-based stress reduction and health benefits: A meta-analysis. Journal of Psychosomatic Research, 57, $35-43$.

Grouzet, F. M. E., Ahuvia, A., Kim, Y., Ryan, R. M., Schmuck, P., Kasser, T., . . Sheldon, K. M. (2005). The structure of goals across 15 cultures. Journal of Personality and Social Psychology, 89(5), 800-816. doi: 10.1037/0022-3514.89.5.800 
Error! No text of specified style in document. The Impact of a Materialistic Value Orientation on Well-Being

Halliwell, E., \& Diedrichs, P. C. (2014). Brief report: Testing a dissonance body image intervention among young girls. Health Psychology, 33 (2), 201-204. doi: $10.1037 / \mathrm{a} 0032585$

Halliwell, E., \& Dittmar, H. (2004). Does size matter? The impact of model's body size on advertising effectiveness and women's body-focused anxiety. Journal of Social and Clinical Psychology, 23, 105-132.

Hardin, G. (1968). The tragedy of the commons. Science, 162, 1243-1248.

Hedlund-de Witt, A., de Boer, J., \& Boersema, J. J. (2014). Exploring inner and outer worlds: A quantitative study of worldviews, environmental attitudes, and sustainable lifestyles. Journal of Environmental Psychology, 37, 40-54.

Hegel, G. W. F. (1807). System der Wissenschaft, Erster Teil: Phänomenologie des Geistes. Bamberg: Goebhart.

Higgins, E. T. (1987). Self-discrepancy: A theory relating self and affect. Psychological Review, 94, 319-340.

Hurst, M., Dittmar, H., Bond, R., \& Kasser, T. (2013). The relationship between materialistic values and environmental attitudes and behaviors: A meta-analysis. Journal of Environmental Psychology, 36, 257-269. doi: 10.1016/j.jenvp.2013.09.003

Hurst, M., Dittmar, H., Halliwell, E., \& Diedrichs, P. C. (2016). Does size matter? Media influences and body image. In C. Jansson-Boyd \& M. Zawiska (Eds.), International handbook of consumer psychology. London: Taylor and Francis.

Inglehart, R. (1990). Culture shift in advanced industrial society. Princeton, NJ: Princeton University Press. 
Error! No text of specified style in document. The Impact of a Materialistic Value Orientation on Well-Being

Jackson, T. (2009). Prosperity without growth: Economics for a finite planet. London: Earthscan.

Kaiser, F. G., \& Byrka, K. (2011). Environmentalism as a trait: Gauging people's prosocial personality in terms of environmental engagement. International Journal of Psychology, 46, 71-79. doi: 10.1080/00207594.2010.516830

Kasser, T. (2002). The high price of materialism. Cambridge, MA: MIT Press.

Kasser, T. (2011). Cultural values and the well-being of future generations: A cross-national study. Journal of Cross-Cultural Psychology, 42(2), 206-215.

Kasser, T. (2016). Materialistic values and goals. Annual Review of Psychology, 67, 489-514.

Kasser, T., \& Ahuvia, A. (2002). Materialistic values and well-being in business students. European Journal of Social Psychology, 32, 137-146. doi: 10.1002/ejsp.85

Kasser, T., Cohn, S., Kanner, A. D., \& Ryan, R. M. (2007). Some costs of American corporate capitalism: A psychological exploration of value and goal conflicts. Psychological Inquiry, 18(1), 1-22.

Kasser, T., Rosenblum, K. L., Sameroff, A. J., Deci, E. L., Niemiec, C. P., Ryan, R. M., . . Hawks, S. (2014). Changes in materialism, changes in psychological well-being: Evidence from three longitudinal studies and an intervention experiment. Motivation and Emotion, 38(1), 1-22. doi: 10.1007/s11031-013-9371-4

Kasser, T., \& Ryan, R. M. (1993). A dark side of the American dream: Correlates of financial success as a central life aspiration. Journal of Personality and Social Psychology, 65, 410-422. doi: 10.1037/0022-3514.65.2.410 
Error! No text of specified style in document. The Impact of a Materialistic Value Orientation on Well-Being

Kasser, T., Ryan, R. M., Zax, M., \& Sameroff, A. J. (1995). The relations of maternal and social environments to late adolescents' materialistic and prosocial values. Developmental Psychology, 31, 907-914. doi: 10.1037/0012-1649.31.6.907

Kasser, T., \& Sheldon, K. M. (2000). Of wealth and death: Materialism, mortality salience, and consumption behavior. Psychological Science, 11, 348-351. doi: 10.1111/14679280.00269

Khanna, S., \& Kasser, T. (2001). Materialism, objectification, and alienation from a crosscultural perspective. Unpublished manuscript.

Ku, L., Dittmar, H., \& Banerjee, R. (2014). To have or to learn? The effects of materialism on British and Chinese children’s learning. Journal of Personality and Social Psychology, 106(5), 803-821. doi: 10.1037/a0036038

Ku, L., Wu, A. M., Lao, A. K., \& Lam, K. I. (2016). "We want the world and we want it now": Materialism, time perspectives and problem spending tendency of Chinese. International Journal of Psychology. Online publication. doi: 10.1002/ijop.12391

$\mathrm{Ku}, \mathrm{L.}$, \& Zaroff, C. (2014). How far is your money from your mouth? The effects of intrinsic relative to extrinsic values on willingness to pay and protect the environment. Journal of Environmental Psychology, 40, 472-483.

LaFontana, K. M., \& Cillessen, A. H. N. (1999). Children's interpersonal perceptions as a function of sociometric and peer-perceived popularity. Journal of General Psychology, $160,225-242$.

LaFontana, K. M., \& Cillessen, A. H. N. (2002). Children's perceptions of popular and unpopular peers: A multimethod assessment. Developmental Psychology, 38, 635-647. 
Error! No text of specified style in document. The Impact of a Materialistic Value Orientation on Well-Being

Lease, A. M., Musgrove, K. T., \& Axelrod, J. L. (2002). Dimensions of social status in preadolescent peer groups: Likeability, perceived popularity and social dominance. Social Development, 11, 508-533.

Lebow, V. (1955). Price competition in 1955. Journal of Retailing. Retrieved from hundredgoals.files.wordpress.com/2009/05/journal-of-retailing.pdf

Lu, L. C., \& Lu, C. J. (2010). Moral philosophy, materialism, and consumer ethics: An exploratory study in Indonesia. Journal of Business, 94(2), 193-210. doi: $10.1007 / \mathrm{s} 10551-009-0256-0$

Maio, G. R. (2015). The psychology of human values. European Monographs in Social Psychology series edited by Rupert Brown. London: Psychology Press.

Maio, G. R., Pakizeh, A., Cheung, W., \& Rees, K. J. (2009). Changing, priming, and acting on values: Effects via motivational relations in a circular model. Journal of Personality and Social Psychology, 97(4), 699-715. doi: 10.1037/a0016420

Maraz, A., Griffiths, M. D., \& Demetrovics, Z. (2016). The prevalence of compulsive buying: A meta-analysis. Addiction, 111(3), 408-419. doi: 10.1111/add.13223

Marx, K. (1867). Das Kapital: Kritik der politischen Ökonomie. Hamburg: Meissner.

Maslow, A. (1943). A theory of human motivation. Psychological Review, 50(4), 370-396. doi: $10.1037 / \mathrm{h} 0054346$

Messick, D. M., \& McClelland, C. L. (1983). Social traps and temporal traps. Personality and Social Psychology Bulletin, 9(1), 105-110.

Mostow, A. J., Izard, C. E., Fine, S., \& Trentacosta, C. J. (2002). Modeling emotional, cognitive, and behavioral predictors of peer acceptance. Child Development, 73, 1775-1787. doi: $10.1111 / 1467-8624.00505$ 
Error! No text of specified style in document. The Impact of a Materialistic Value Orientation on Well-Being

Neuner, M., Raab, G., \& Reisch, L. A. (2005). Compulsive buying in maturing consumer societies: An empirical re-inquiry. Journal of Economic Psychology, 26, 509-522. doi: 10.1016/j.joep.2004.08.002

O’Donahue, J. (2014). Benedictus: A book of blessings. London: Bantam.

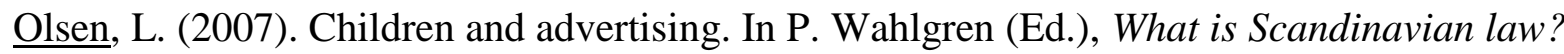
(pp. 436-461). Stockholm: Stockholm Institute for Scandinavian Law.

Opree, S. J., Buijzen, M., \& Valkenburg, P. M. (2012). Lower life satisfaction related to materialism in children frequently exposed to advertising. Pediatrics, 130, 486-491.

Parker, J. G., \& Gottman, J. M. (1989). Social and emotional development in a relational context: Friendship interaction from early childhood to adolescence. In J. T. Berndt \& G. W. Ladd (Eds.), Peer relationships in child development (pp. 95-131). Oxford: Wiley.

Parkhurst, J. T., \& Hopmeyer, A. (1998). Sociometric popularity and peer-perceived popularity: Two distinct dimensions of peer status. Journal of Early Adolescence, 18, 125-144.

Paxton, S. J. (2015). Social policy and prevention. In M. Levine \& L. Smolak (Eds.), The WileyBlackwell handbook of eating disorders (pp. 655-668). Chichester, UK: Wiley.

Pilch, I., \& Durnik-Durose, E. M. (2016). Do we need "dark" traits to explain materialism? The incremental validity of the Dark Triad over the HEXACO domains in predicting materialistic orientation. Personality and Individual Differences, 102, 102-106. doi: 10.1016/j.paid.2016.06.047

Richins, M. L. (2004). The material values scale: Measurement properties and development of a short form. Journal of Consumer Research, 31, 209-219. doi: 10.1086/383436 
Error! No text of specified style in document. The Impact of a Materialistic Value Orientation on Well-Being

Richins, M. L., \& Dawson, S. (1992). A consumer values orientation for materialism and its measurement: Scale development and validation. Journal of Consumer Research, 19, 303-316. doi: 10.1086/209304

Rindfleisch, A., Burroughs, J. E., \& Denton, F. (1997). Family structure, materialism, and compulsive consumption. Journal of Consumer Research, 23, 312-325.

Roberts, J. A., \& Roberts, C. R. (2012). Money matters: Does the symbolic presence of money affect charitable giving and attitudes among adolescents? Young Consumers, 13(4), 329336. doi: $10.1108 / 17473611211282572$

Rokeach, M. (1973). The nature of human values. New York: Free Press.

Ryan, R. M., \& Deci, E. L. (2000). Self-determination theory and the facilitation of intrinsic motivation, social development, and well-being. American Psychologist, 55(1), 68-78.

Sagiv, L., \& Schwartz, S. (2000). Value priorities and subjective well-being: Direct relations and congruity effects. European Journal of Social Psychology, 30(2), 177-198. doi: 10.1002/(SICI)1099-0992(200003/04)

Schwartz, S. H. (1992). Universals in the content and structure of values: Theoretical advances and empirical tests in 20 countries. In M. P. Zanna (Ed.), Advances in experimental social psychology (Vol. 25, pp. 1-654). Orlando, FL: Academic Press.

Schwartz, S. H. (2012). An overview of the Schwartz theory of basic values. Online Readings in Psychology and Culture, 2(1). doi: 10.9707/2307-0919.1116

Sheldon, K. M., \& Kasser, T. (2008). Psychological threat and extrinsic goal striving. Motivation and Emotion, 32, 37-45. 
Error! No text of specified style in document. The Impact of a Materialistic Value Orientation on Well-Being

Sheldon, K. M., Nichols, C. P., \& Kasser, T. (2011). Americans recommend smaller ecological footprints when reminded of intrinsic American values of self-expression, family, and generosity. Ecopsychology, 3, 97-104. doi: 10.1089/eco.2010.0078

Stice, E. (2002). Risk and maintenance factors for eating pathology: A meta-analytic review. Psychological Bulletin, 128(5), 825-848.

Strizhakova, Y., \& Coulter, R. A. (2013). The "green" side of materialism in emerging BRIC and developed markets: The moderating role of global cultural identity. International Journal of Research in Marketing, 30(1), 69-82.

Sweney, M. (2011, November 25). Humbug: Littlewoods Christmas ad causes hundreds to complain to ASA. Guardian. Last retrieved March 16, 2017 from www.theguardian.com/media/2011/nov/25/littlewoods-christmas-ad-complaints

Twenge, J. M., Gentile, B., DeWall, C. N., Ma, D. S., Lacefield, K., Schurtz, D. R. (2010). Birth cohort increases in psychopathology among young Americans, 1938-2007: A crosstemporal meta-analysis of the MMPI. Clinical Psychology Review, 30, 145-154.

Twenge, J. M., \& Kasser, T. (2013). Generational changes in materialism and work centrality, 1976-2007: Associations with temporal changes in societal insecurity and materialistic role modelling. Social Psychology and Personality Bulletin, 39(7), 883-897. doi: $10.1177 / 0146167213484586$

Unanue, W., Vignoles, V. L., Dittmar, H., \& Vansteenkiste, M. (2016). Life goals predict environmental behavior: Cross-sectional and longitudinal evidence. Journal of Environmental Psychology, 46, 10-22. doi: 10.1016/j.jenvp.2016.02.001 
Error! No text of specified style in document. The Impact of a Materialistic Value Orientation on Well-Being

Van Lange, P. A. M. (1999). The pursuit of joint outcomes and equality in outcomes: An integrative model of social value orientation. Journal of Personality and Social Psychology, 77, 337-349. doi: 10.1037/0022-3514.77.2.337

Wapner, S., Demick, J., \& Redondo, J. P. (1990). Cherished possessions and adaption of older people to nursing homes. International Journal of Aging and Human Development, 31, $219-235$.

Watson, J. J. (2003). The relationship of materialism to spending tendencies, saving, and debt. Journal of Economic Psychology, 24, 723-739.

Weinstein, N., Przybylski, A. K., \& Ryan, R. M. (2009). Can nature make us more caring? Effects of immersion in nature on intrinsic aspirations and generosity. Personality and Social Psychology Bulletin, 35, 1315-1329. doi: 10.1177/0146167209341649

White, M. C. (2014). Here's proof buying more stuff actually makes you miserable. Time, 13th March. Retrieved from http://time.com/22257/heres-proof-buying-more-stuff-actually$\underline{\text { makes-you-miserable/ }}$

Wright, M., Hurst, M., Dittmar, H., \& Banerjee (2017). “Having cool stuff” and “looking good": A qualitative study on children's beliefs and motives. MS in preparation, University of Brighton and University of Sussex.

Zamanpour, N., Dittmar, H., Döring, A. K., Mendese, A., \& Hurst, M. (2017). Sustainable consumers of the future? A school-based intervention to increase children's proenvironmentalism. Journal of Environmental Psychology, under editorial consideration. 
Error! No text of specified style in document. The Impact of a Materialistic Value Orientation on Well-Being

1 Consumer culture values include both a materialistic orientation and an idealized body orientation, IBO for short, internalizing a thin (for women) or muscular (for men) body shape ideal as a personal value 